\title{
Ketamine Depresses Toll-Like Receptor 3 Signaling in Spinal Microglia in a Rat Model of Neuropathic Pain
}

\author{
Xiao-Peng Mei ${ }^{\mathrm{a}, \mathrm{b}}$ Yang Zhou ${ }^{\mathrm{a}, \mathrm{b}} \quad$ Wei Wang $^{\mathrm{b}} \quad$ Jun Tang $^{\mathrm{a}}$ Wen Wang ${ }^{\mathrm{b}}$

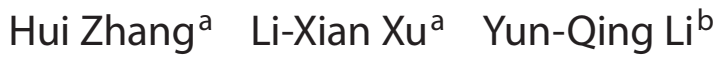 \\ ${ }^{a}$ Department of Anesthesiology, School of Stomatology, and ${ }^{b}$ Department of Anatomy, Histology and Embryology, \\ K.K. Leung Brain Research Centre, Fourth Military Medical University, Xi'an, PR China
}

\section{Key Words}

Glia $\cdot$ Microglia $\cdot$ Mitogen-activated protein kinase •

Toll-like receptor $\cdot$ Analgesic

\begin{abstract}
Reports suggest that microglia play a key role in spinal nerve ligation (SNL)-induced neuropathic pain, and toll-like receptor 3 (TLR3) has a substantial role in the activation of spinal microglia and the development of tactile allodynia after nerve injury. In addition, ketamine application could suppress microglial activation in vitro, and ketamine could inhibit proinflammatory gene expression possibly by suppressing TLR-mediated signal transduction. Therefore, the present study was designed to disclose whether intrathecal ketamine could suppress SNL-induced spinal microglial activation and exert some antiallodynic effects on neuropathic pain by suppressing TLR3 activation. Behavioral results showed that intrathecal ketamine attenuated SNL-induced mechanical allodynia, as well as spinal microglial activation, in a dose-dependent manner. Furthermore, Western blot analysis displayed that ketamine application downregulated SNL-induced phosphorylated-p38 (p-p38) expression, which was specifically expressed in spinal microglia but not in astrocytes or neurons. Besides, ketamine could reverse TLR3
\end{abstract}

agonist (polyinosine-polycytidylic acid)-induced mechanical allodynia and spinal microglia activation. It was concluded that intrathecal ketamine depresses TLR3-induced spinal microglial p-p38 mitogen-activated protein kinase pathway activation after SNL, probably contributing to the antiallodynic effect of ketamine on SNL-induced neuropathic pain.

Copyright $\odot 2011$ S. Karger AG, Basel

\section{Introduction}

Millions of people worldwide suffer from neuropathic pain, which is an intractable clinical problem [1]. It has been reported that ketamine, a noncompetitive blocker for the glutamate N-methyl-D-aspartate (NMDA) receptor, can be applied for treating neuropathic pain both in clinical and lab settings [2-4]. Much research has been carried out to disclose the underlying mechanisms of ketamine analgesia, which are still not fully understood. Studies have suggested that NMDA receptors, the monoaminergic descending inhibitory system, opioid recep-

X.-P.M., Y.Z., and W.W. contributed equally to this work.

\section{KARGER}

Fax +4161306 1234

E-Mail karger@karger.ch

www.karger.com
(C) 2011 S. Karger AG, Basel

1424-862X/11/0191-0044\$38.00/0

Accessible online at:

www.karger.com/nsg
Dr. Li-Xian Xu

Department of Anesthesiology, School of Stomatology

Fourth Military Medical University, No. 169, West Changle Road

Xi'an 710032 (PR China), Tel. +86 298477 6115, E-Mail kqmzk@126.com

also Dr. Hui Zhang fuming@fmmu.edu.cn 
tors, nicotinic receptors, voltage-gated ion channels, and the gamma-aminobutyric acid (GABA) receptor are all involved in the analgesia of ketamine [2, 3, 5-9]. Very interestingly, some other studies have suggested that glia are also involved in opioid receptor, NMDA receptor, serotonergic receptor, and GABA receptor function [1013]. Therefore, the morphology and signaling pathways in glial cells may also be affected by ketamine.

Thanks to decades of investigations, spinal glial cells (microglia and astrocytes) have been implicated as key factors not only in the induction but also in the maintenance of neuropathic pain [14-19]. Spinal microglia have been reported to take part directly in the initiation of peripheral nerve injury-induced neuropathic pain $[1,14$, 20]. A previous study confirmed that toll-like receptor 3 (TLR3)-induced spinal dorsal horn microglia p38 mitogen-activated protein kinase (MAPK) activation contributes to the development of spinal nerve ligation (SNL)induced neuropathic pain [21]. Moreover, spinal microglia could release some proinflammatory factors such as interleukin-1, tumor necrosis factor (TNF), and various chemokines during the development of neuropathic pain [22-25]. Interestingly, recent in vitro studies reported that ketamine could inhibit lipopolysaccharide (LPS)-induced microglia activation to exert some anti-inflammatory effects by blocking MAPK pathway activation [26, 27]. In addition, studies confirmed that ketamine could inhibit inflammatory reaction by suppressing the function of TLR [27-30]. Based on the results of those studies, we hypothesized that depressing TLR3-induced spinal microglia MAPK pathway activation may contribute to the antiallodynic effects of ketamine on neuropathic pain.

In the present study, the effects of ketamine on SNL or TLR3 agonist-induced mechanical allodynia were confirmed by behavioral testing. SNL-induced spinal microglia activation was detected by immunofluorescent histochemistry. Subsequently, the variation of microglia activation was investigated after the application of drugs. Finally, the microglia p38 MAPK pathway was investigated by immunofluorescent histochemistry and Western blot after different treatments.

\section{Materials and Methods}

\section{Animal Preparation}

Male Sprague-Dawley rats (180-200 g) were housed in plastic cages and maintained on a 12:12 h light/dark cycle under conditions of $22-25^{\circ} \mathrm{C}$ ambient temperature with food and water available. All experimental procedures received prior approval from the Animal Use and Care Committee for Research and Education of the Fourth Military Medical University (Xi'an, China), and the ethical guidelines to investigate experimental pain in conscious animals were followed [31]. Every effort was made to minimize animal suffering and to restrict the number of animals used.

\section{Intrathecal Implantation and Drug Administration}

Intrathecal implantation was performed by inserting polyethylene (PE) tubing to inject the drug directly into the subarachnoid space of the lumbar enlargement. Briefly, a midline incision $(3 \mathrm{~cm})$ was made at the back of the rat at the level of the thoracic vertebrae under pentobarbital anesthesia $(45 \mathrm{mg} / \mathrm{kg}$, i.p.). A premeasured length of PE-10 tubing (inner diameter $0.28 \mathrm{~mm}$ and outer diameter $0.61 \mathrm{~mm}$ ) was passed caudally from the T8 level to the $\mathrm{L} 3$ level of the spinal cord; $2 \mathrm{~cm}$ of it was left exposed in the upper thoracic region. The rats were allowed to recover for 3-5 days before further use. Only the animals judged as neurologically normal and showing complete paralysis of both hind legs and tail after administration of $2 \%$ lidocaine $(10 \mu \mathrm{l})$ through the intrathecal catheter were used for the subsequent experiments.

S-(+)-ketamine hydrochloride (Sigma, St. Louis, Mo., USA) was dissolved and diluted with preservative-free normal saline solution for administration. Normal saline $(0.9 \%)$ was used as the negative control. Animals were divided into the following 4 groups for administration: sham-saline, SNL-saline, SNL-ketamine, and sham-ketamine. Drugs and normal saline were injected intrathecally over $30 \mathrm{~s}$, followed by a $10-\mu \mathrm{l}$ flush of normal saline.

Polyinosine-polycytidylic acid (poly I:C; Sigma) was injected intrathecally $(100 \mu \mathrm{g}, 10 \mu \mathrm{l})$ to the normal rats, followed by ketamine $(300 \mu \mathrm{g} / \mathrm{kg}, 10 \mu \mathrm{l})$ or normal saline $(10 \mu \mathrm{l})$. The dosages of ketamine and poly I:C used in the present study were in accordance with previous research $[2,21,32]$ and our pilot experiment.

\section{Spinal Nerve Ligation}

To create the SNL model, the left L6 transverse process was first removed to expose the L4 and L5 spinal nerves under pentobarbital anesthesia ( $45 \mathrm{mg} / \mathrm{kg}$, i.p.). The $\mathrm{L} 5$ spinal nerve was then carefully isolated and tightly ligated with 6-0 silk thread [33]. The surgical procedure for the sham group was identical to that of the SNL group, except that the spinal nerve was not ligated.

\section{Nociceptive Behavioral Tests}

The animals were acclimatized to the testing environment for 3 days before baseline testing; they were then placed under inverted plastic boxes $\left(30 \times 30 \times 50 \mathrm{~cm}^{3}\right)$ on an elevated mesh floor and allowed habituation for $30 \mathrm{~min}$ before threshold testing. Room temperature $\left(22-25^{\circ} \mathrm{C}\right)$ and humidity remained stable for all experiments. An electronic von Frey anesthesiometer (model 23905 , blunt polypropylene tip, diameter $0.5 \mathrm{~mm}$; IITC Life Science, Woodland Hills, Calif., USA) was used to determine the mechanical threshold. Behavioral testing was performed blindly with respect to drug administration. A paw flick response was elicited by applying increasing force (measured in g) using a plastic filament focused on the middle of the plantar surface of the ipsilateral hind paw. The force applied was initially below the detection threshold; it was increased from 1 to $50 \mathrm{~g}$ in 0.1 -gram steps over $20 \mathrm{~s}$ and then maintained at $50 \mathrm{~g}$ for a further $10 \mathrm{~s}$. The rate of force increase was $2.5 \mathrm{~g} / \mathrm{s}$. The threshold was taken as the force applied to elicit a reflex removal of the hind paw. The cutoff value was $50 \mathrm{~g}$. This was defined as the mean of 3 measurements at 1-min intervals. 


\section{Immunofluorescence}

After deep anesthesia produced with pentobarbital $(60 \mathrm{mg} / \mathrm{kg}$, i.p.), the rats were perfused through the ascending aorta with 100 $\mathrm{ml} 0.9 \%$ saline followed by $500 \mathrm{ml} 0.1 \mathrm{M}$ phosphate buffer ( $\mathrm{pH} 7.3$ ) that contained $4 \%$ paraformaldehyde and $2 \%$ picric acid. After perfusion, the L5 spinal segment was removed and postfixed in the same fixative for $2-4 \mathrm{~h}$ and then cryoprotected for $24 \mathrm{~h}$ at $4^{\circ} \mathrm{C}$ in $0.1 \mathrm{M}$ phosphate buffer that contained $30 \%$ sucrose. Transverse frozen spinal sections (30 $\mu \mathrm{m}$ thick) were cut in a cryostat (CM1800; Leica, Heidelberg, Germany) and collected serially in 3 dishes. Each dish contained a complete set of serial sections that were processed for immunofluorescent staining. One of the dishes was selected randomly. The sections in that dish were rinsed in $0.01 \mathrm{M}$ phosphate-buffered saline (PBS, pH 7.3) 3 times (10 min each), blocked with $2 \%$ goat serum in $0.01 \mathrm{M}$ PBS that contained $0.3 \%$ Triton $\mathrm{X}-100$ for $1 \mathrm{~h}$ at room temperature, and then used for immunofluorescent staining.

The sections were incubated with primary antibodies, i.e. mouse anti-OX42 (1:500; Abcam, Cambridge, UK) and rabbit anti-phosphorylated p38 (p-p38) antibody (1:500; Cell Signaling Technology, Beverly, Mass., USA) overnight at $4{ }^{\circ} \mathrm{C}$. Other primary antibodies used in this study were monoclonal antibodies, i.e. mouse anti-neuronal-specific nuclear protein (NeuN) (1:3,000; Chemicon, Temecula, Calif., USA) and mouse anti-glial fibrillary acidic protein (GFAP) (1:5,000; Chemicon). For double immunofluorescence, sections were incubated with a mixture of 2 primary antibodies followed by a mixture of the 2 respective secondary antibodies (Alexa 488 donkey anti-rabbit IgG and Alexa 594 donkey anti-mouse IgG, 1:500; Invitrogen, Carlsbad, Calif., USA). The specificity of the staining was tested on the sections in another dish by omission of the primary specific antibodies. No immunoreactive products were found on the sections (data not shown). Confocal images were obtained using a confocal laser microscope (FV1000; Olympus, Tokyo, Japan; 1 - $\mu$ m-thick optical section), and digital images were captured with a Fluoview 1000 (Olympus).

\section{Western Blot}

All animals were rapidly sacrificed and the L5 dorsal horns were promptly removed and frozen on dry ice. The spinal dorsal horn was dissected using the open-book method [34]. The selected region was homogenized with a hand-held pestle in SDS sample buffer $(10 \mathrm{ml} / \mathrm{mg}$ tissue) which contained a cocktail of proteinase and phosphatase inhibitors. The electrophoresis samples were heated at $100^{\circ} \mathrm{C}$ for $5 \mathrm{~min}$ and loaded onto $10 \%$ SDS-polyacrylamide gels with standard Laemmli solutions (Bio-Rad Laboratories, Hercules, Calif., USA). The proteins were electroblotted onto polyvinylidene difluoride membranes (Immobilon-P; Millipore, Billerica, Mass., USA). The membranes were placed for $1 \mathrm{~h}$ in a blocking solution which contained Tris-buffered saline with $0.02 \%$ Tween (TBS-T) and 5\% nonfat dry milk, and they were incubated for 2 nights at $4{ }^{\circ} \mathrm{C}$ under gentle agitation with primary antibodies, i.e. rabbit anti-p-p38 antibody $(1: 1,000$ in $5 \%$ BSA; Cell Signaling Technology) and mouse anti- $\beta$-actin (1:1,000; Sig$\mathrm{ma})$, respectively. Bound primary antibodies were detected with the anti-rabbit or anti-mouse horseradish peroxidase (HRP)-conjugated secondary antibody (1:10,000; Amersham Pharmacia Biotech, Inc., Piscataway, N.J., USA). After each step, the immunoblots were rinsed with TBS-T. All reactions were detected using the enhanced chemiluminescence (ECL) detection method (Am- ersham). The densities of protein blots were analyzed using Labworks software (Ultra-Violet Products, UK). The densities of p-p38 and $\beta$-actin immunoreactive bands were quantified with background subtraction. A square of the same size was drawn around each band to measure the density, and the background near that band was subtracted. Since $\beta$-actin levels did not change significantly after inflammation and nerve injury [35], we used $\beta$-actin levels as a loading control and the p-p38 level was normalized against $\beta$-actin levels.

\section{Quantification and Statistical Analysis}

Data from immunofluorescence were calculated as detailed in our previous report [36]. For the quantification of OX42 immunopositive cell profiles in the spinal cord, 5 nonadjacent sections $(30 \mu \mathrm{m})$ from the $\mathrm{L} 5 \mathrm{segments}$ were selected randomly from each animal. In each group, 6 rats were used for statistical analysis. An image $\left(450 \times 338 \mu \mathrm{m}^{2}\right)$ of the medial two thirds of the superficial dorsal horn (laminas I to III) was captured under a $20 \times$ objective [19]. All of the positively stained cells in the area were evaluated by a computer-assisted image analysis program (MetaMorph 6.1) which set the low and high thresholds for the immunofluorescent intensity which was determined to be a signal. The same configuration was used to measure cell areas in all experimental groups. The measured areas were transferred to Excel automatically for the following statistical analysis. MetaMorph 6.1 is calibrated to provide standardization of area measurements. A standardized field area was sampled arbitrarily from regions within randomly selected dorsal horn sections [19]. Data from immunofluorescence were expressed as a fold change against that of the shamsaline (or saline-saline) group. ANOVA followed by the least significant difference test was used for statistical analysis.

Double-labeled cells were counted on 6 sections randomly selected from 6 rats ( 1 section per animal) after superposition of the 2 images from the same field but with different markers.

All data are presented as means \pm SD and were collected by researchers blinded to the surgery and reagents used. Data from the Western blot were tested using one-way ANOVA followed by the least significant difference test. Data from the von Frey test were analyzed by repeated measures ANOVAs followed by Fisher's protected least significant difference post hoc comparisons where appropriate. All statistical analyses were performed using SPSS $^{\circledR}$ version 16.0 software (SPSS, Inc., Chicago, Ill., USA). p < 0.05 was considered statistically significant.

\section{Results}

\section{Ketamine Relieved SNL-Induced Mechanical}

\section{Allodynia in a Dose-Dependent Manner}

In order to detect the effects of intrathecal ketamine on SNL-induced mechanical allodynia, ketamine was injected once a day at 3 different dosages (30, 100, and 300 $\mu \mathrm{g} / \mathrm{kg}$ ), and changes in the paw withdrawal threshold (PWT) were observed $30 \mathrm{~min}$ after injection and from postoperative day (POD) 0 to POD 3.

SNL could induce rapid and significant mechanical allodynia as shown in the SNL-saline group (fig. 1). In- 


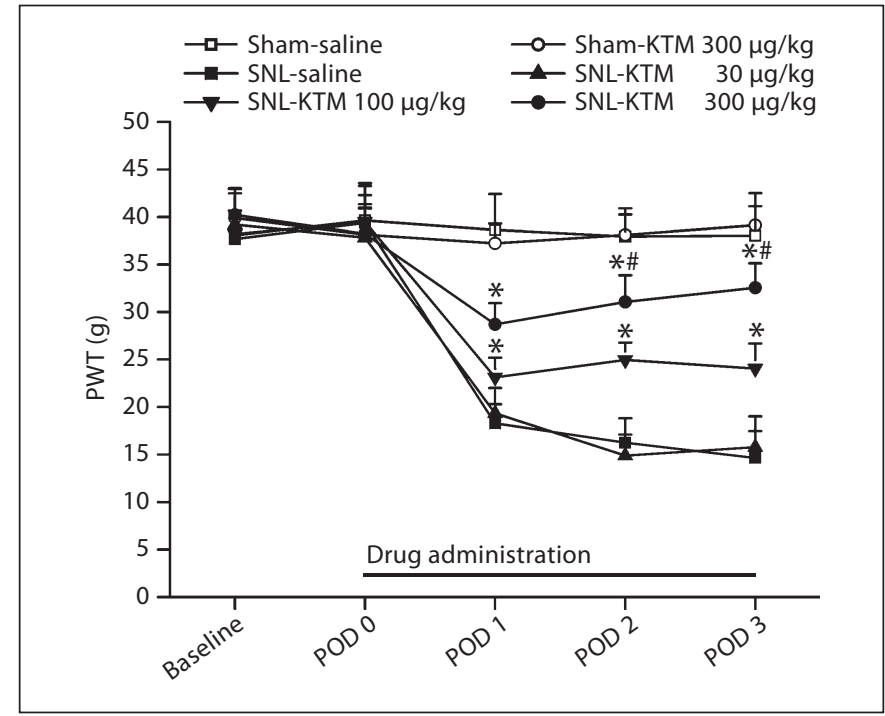

Fig. 1. Effect of intrathecal ketamine (KTM) on SNL-induced neuropathic mechanical allodynia. SNL could induce significant mechanical allodynia shown by the pain behavioral tests. Ketamine application (100 and $300 \mu \mathrm{g} / \mathrm{kg}$ ) showed an effective and reliable antiallodynia effect in a dose-dependent manner on SNLinduced mechanical allodynia, whereas intrathecal ketamine 30 $\mu \mathrm{g} / \mathrm{kg}$ did not affect the pain threshold after SNL. Additionally, intrathecal ketamine $300 \mu \mathrm{g} / \mathrm{kg}$ had no effect on the normal pain threshold of the sham-operated group. Drugs were given intrathecally once a day from POD 0 to POD $3 .{ }^{*} \mathrm{p}<0.05 \mathrm{vs}$. SNL-saline. ${ }^{\#} \mathrm{p}<0.05 \mathrm{vs}$. SNL-ketamine $100 \mu \mathrm{g} / \mathrm{kg}$. There were $12 \mathrm{rats}$ in each group.

trathecal ketamine $(30 \mu \mathrm{g} / \mathrm{kg})$ did not obviously influence the PWT. However, intrathecal ketamine $(100 \mu \mathrm{g} /$ $\mathrm{kg}$ ) elevated the PWT significantly after administration $(\mathrm{p}<0.05$ vs. SNL-saline). Moreover, a higher dose of ketamine $(300 \mu \mathrm{g} / \mathrm{kg})$ relieved the allodynia ( $\mathrm{p}<0.05 \mathrm{vs}$. SNL-ketamine $100 \mu \mathrm{g} / \mathrm{kg}$ ). In addition, neither a high dose $(300 \mu \mathrm{g} / \mathrm{kg}$ ) nor a lower dose (30 and $100 \mu \mathrm{g} / \mathrm{kg}$, data not shown) of ketamine affected the basal threshold in the sham-operated group. All of these results suggest that intrathecal ketamine $(30,100$, and $300 \mu \mathrm{g} / \mathrm{kg})$ exerted an effective and reliable effect on SNL-induced mechanical allodynia in a dose-dependent manner.

\section{Ketamine Attenuated SNL-Induced Microglia \\ Activation in the Ipsilateral Spinal Dorsal Horn}

SNL induced marked microglia activation in the ipsilateral spinal dorsal horn (fig. 2a), while only a few positive cells could be detected in the contralateral spinal dorsal horn 3 days after SNL (fig. 2b). The expression of spinal microglial OX42 was very low in the sham-saline
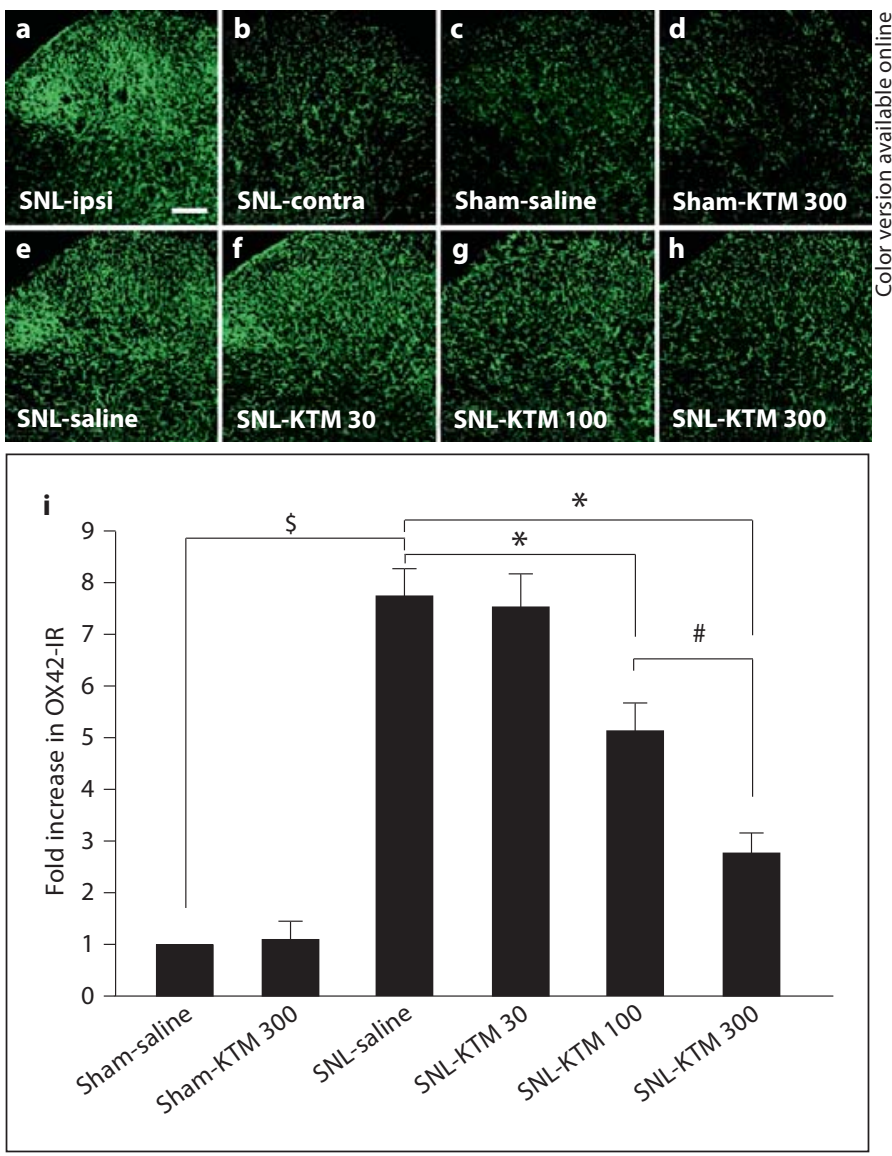

Fig. 2. Effect of intrathecal ketamine (KTM) on SNL-induced spinal microglia activation. SNL induced remarkable spinal microglia activation indicated by OX42 upexpression in the ipsilateral (ipsi) dorsal horn (a) vs. the contralateral (contra) side (b). The spinal microglia activation level is low in the ipsilateral dorsal horn in the sham-operated rat (c), and intrathecal ketamine 300 $\mu \mathrm{g} / \mathrm{kg}$ did not have any obvious effect on microglia activation (d). SNL-induced microglia activation is confirmed by the higher expression of OX42 (e). Intrathecal administration of ketamine (30, 100 , and $300 \mu \mathrm{g} / \mathrm{kg}$ ) indicates suppressive effects on SNL-induced microglia activation in a dose-dependent manner (f-h). i Statistical analysis of spinal microglia activation after different treatments with the density of OX42 expression. * * , and \$ each indicate a statistically significant difference with $\mathrm{p}<0.05$ between groups. There were 6 rats in each group. Scale bar $=100 \mu \mathrm{m}$.

group (fig. 2c) and in the group which received shamketamine $300 \mu \mathrm{g} / \mathrm{kg}$ (fig. 2d). Compared with the shamsaline group, SNL induced a much higher expression of OX42 in the spinal dorsal horn (SNL-saline group; fig. 2e) as indicated by the increased density of immunoreactive staining (fig. 2i).

Ketamine $(30,100$, and $300 \mu \mathrm{g} / \mathrm{kg})$ inhibited SNL-induced spinal microglia activation in a dose-dependent 
manner ( $p<0.05$ compared with SNL-saline; fig. $2 \mathrm{i})$. Intrathecal ketamine $(30 \mu \mathrm{g} / \mathrm{kg})$ did not have any obvious effect on SNL-induced spinal microglia activation (fig. 2f), but higher doses (100 and $300 \mu \mathrm{g} / \mathrm{kg}$ ) significantly attenuated SNL-induced spinal microglia activation after administration (fig. $2 \mathrm{~g}, \mathrm{~h}$ ).

\section{SNL Induced Significant Upregulation of p-p38 in the} Ipsilateral Spinal Dorsal Microglia

SNL induced remarkable p-p38 upregulation in the ipsilateral spinal dorsal horn (fig. 3a) compared with that in the contralateral spinal dorsal horn (fig. 3b) 3 days after SNL.

In order to detect the cellular localization of p-p38 expression, double immunofluorescent staining with antibodies against p-p38 and neuronal marker NeuN, microglial specific marker OX42, and astrocytic specific marker GFAP was performed. The double immunolabeled cells were counted (table 1). No colocalization could be observed either between p-p38 and NeuN (fig. 3c-e) or between p-p38 and GFAP (fig. $3 \mathrm{f}-\mathrm{h}$ ), which suggests that neither neurons nor astrocytes expressed p-p38 in the spinal dorsal horn 3 days after SNL. However, almost all p-p38-positive cells were OX42-positive microglia (fig. 3ik). p-p38-positive staining was localized in the cell body, which was surrounded by the OX42-positive staining and localized in the cell membrane or processes (fig. 31-n).

\section{Intrathecal Ketamine Downregulated SNL-Induced p-p38 Expression}

We then tested whether intrathecal ketamine had an effect on the spinal microglia p38 signal pathway. The results from the Western blot showed that SNL induced an upregulation of p-p38 in the spinal dorsal horn in the $\mathrm{SNL}$-saline group vs. the sham-saline group $(\mathrm{p}<0.05$; fig. 4). Intrathecal ketamine $30 \mu \mathrm{g} / \mathrm{kg}$ did not affect p-p38 expression compared with that in SNL-saline group (fig. 4). However, intrathecal ketamine $100 \mu \mathrm{g} / \mathrm{kg}$ significantly attenuated the expression of p-p38 (p $<0.05$ vs. the SNL-saline group; fig. 4). Intrathecal injection of ketamine $300 \mu \mathrm{g} / \mathrm{kg}$ apparently downregulated p-p38 expression ( $\mathrm{p}<0.05 \mathrm{vs}$. the SNL-saline group; fig. 4 ), which indicates that ketamine $(300 \mu \mathrm{g} / \mathrm{kg})$ showed stronger inhibition effects on p-p38 expression compared with SNLketamine $100 \mu \mathrm{g} / \mathrm{kg}$ (p<0.05; fig. 4). However, ketamine $(300 \mu \mathrm{g} / \mathrm{kg})$ did not show any effect on p-p38 expression in sham-operated rats compared with the sham-saline group (fig. 4). These results showed that intrathecal ketamine has a dose-dependent effect on the suppression of SNL-induced p-p38 upregulation in spinal dorsal horn.
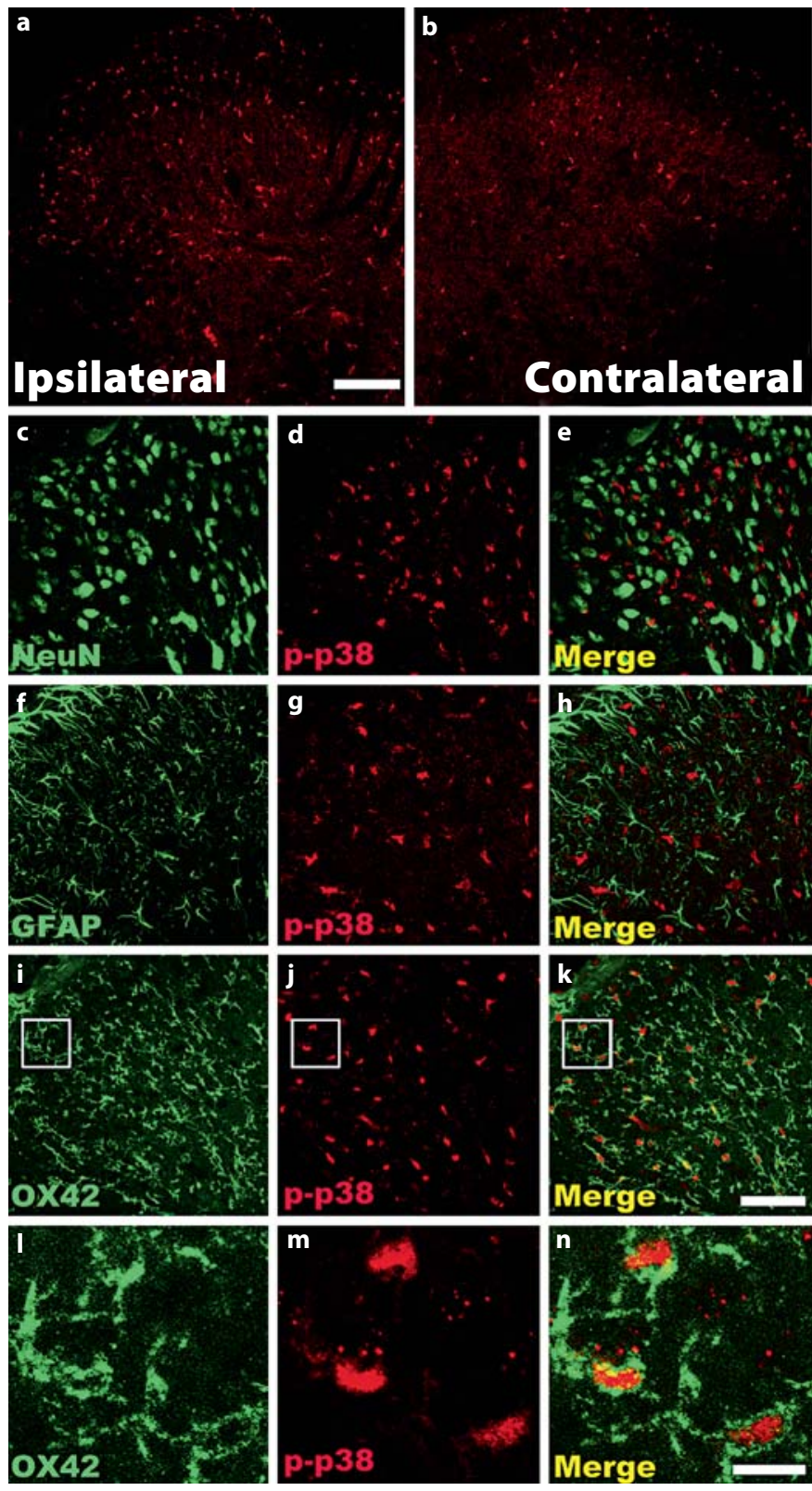

Fig. 3. SNL-induced p-p38 expression and cellular localization in the spinal dorsal horn. SNL induced remarkable p-p38 upregulation in the ipsilateral spinal dorsal horn (a) vs. the contralateral spinal dorsal horn (b). High-magnification images demonstrating double immunofluorescent staining between $\mathrm{NeuN}$ and p-p38 (c-e), glial fibrillary acidic protein (GFAP), and p-p38 (f-h), or between OX42 and p-p38 (i-k). I-n Images were individually captured from i-k showing the colocalization of OX42 and p-p38. Scale bars $=100 \mu \mathrm{m}(\mathbf{a}, \mathbf{b}), 50 \mu \mathrm{m}(\mathbf{c}-\mathbf{k})$, and $10 \mu \mathrm{m}(\mathbf{I}-\mathbf{n})$. 


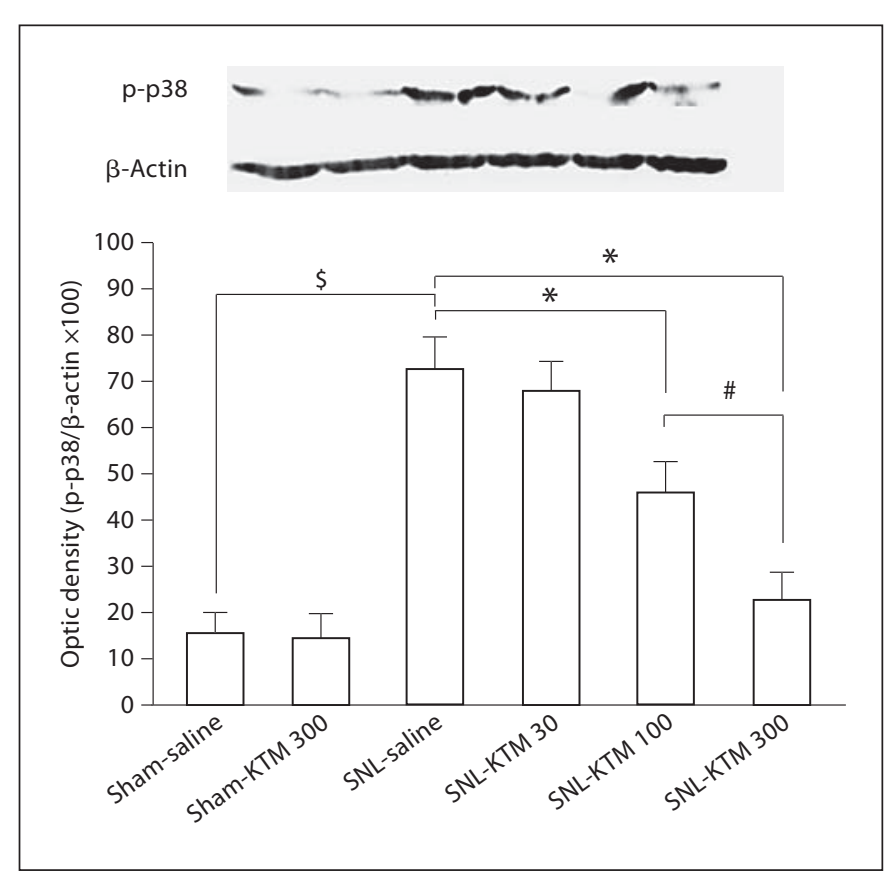

Fig. 4. Effect of different treatments on ipsilateral spinal dorsal horn p-p38 expressions. There was no obvious difference in p-p38 expression after intrathecal $300 \mu \mathrm{g} / \mathrm{kg}$ ketamine (KTM) in sham-operated rats vs. the sham-saline group. p-p38 was apparently upregulated in the SNL-saline group. Ketamine administration effectively decreased p-p38 expression in a dose-dependent manner. ${ }^{*}, *$, and $\$$ each indicate a statistically significant difference with $\mathrm{p}<0.05$ between groups. There were 6 rats in each group.

Table 1. Quantitation of double immunofluorescent staining between p-p38 and NeuN, GFAP, or OX42

\begin{tabular}{lll}
\hline & p-p38-positive cells, $n$ & Double-labeled cells, $\mathrm{n}$ \\
\hline NeuN group & $47 \pm 7$ & $0(\mathrm{p}-\mathrm{p} 38 / \mathrm{NeuN})$ \\
GFAP group & $45 \pm 7$ & $0(\mathrm{p}-\mathrm{p} 38 / \mathrm{GFAP})$ \\
OX42 group & $51 \pm 5$ & $51 \pm 5(\mathrm{p}-\mathrm{p} 38 / \mathrm{OX} 42)$ \\
\hline
\end{tabular}

Values are presented as means \pm SD. There were 6 rats in each group.

\section{Ketamine Reversed Poly I:C Injection-Induced}

Mechanical Allodynia and Spinal Dorsal Microglia

Activation

In order to verify whether TLR3 was involved in the inhibiting effects of ketamine on neuropathic pain, we intrathecally injected a kind of TLR3 agonist poly I:C

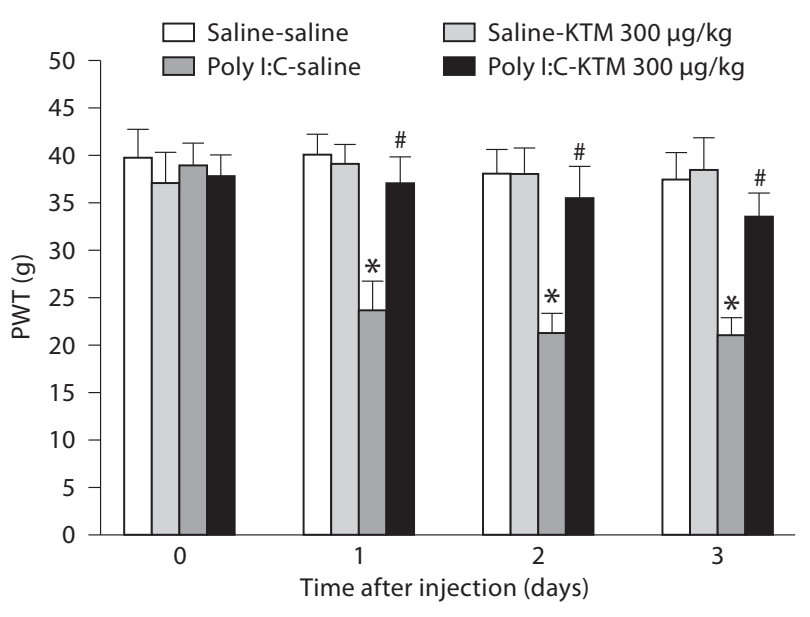

Fig. 5. Effect of intrathecal ketamine (KTM) on poly I:C injectioninduced neuropathic mechanical allodynia. Intrathecal poly I:C $(100 \mu \mathrm{g})$ induced marked mechanical allodynia shown by the pain behavioral tests. Ketamine administration $(300 \mu \mathrm{g} / \mathrm{kg}) \mathrm{did}$ not affect the pain threshold of normal rats but reversed poly I:Cinduced mechanical allodynia. Drugs were given intrathecally only once and the behavioral test was performed during the following 3 days. ${ }^{*} \mathrm{p}<0.05$ vs. the saline-saline group. ${ }^{*} \mathrm{p}<0.05$ vs. the poly I:C-saline group. There were 6 rats in each group.

$(100 \mu \mathrm{g}, 10 \mu \mathrm{l})$ together with ketamine $(300 \mu \mathrm{g} / \mathrm{kg}, 10 \mu \mathrm{l})$ into the normal rats and observed the changes in PWT during the following 3 days. Subsequently, microglia activation was detected.

Poly I:C induced significant mechanical allodynia shown in the poly I:C-saline group 1 day after injection ( $p<0.05$ vs. the saline-saline group; fig. 5). Intrathecal ketamine $(300 \mu \mathrm{g} / \mathrm{kg})$ obviously reversed poly I:C-induced mechanical allodynia ( $\mathrm{p}<0.05$ vs. poly $\mathrm{I}$ :C-saline). Moreover, poly I:C induced significant microglia activation in the spinal dorsal horn 3 days after injection (fig. 6c). There was no marked microglia activation in the saline-saline group (fig. $6 \mathrm{a}$ ) or in the group receiving saline-ketamine $300 \mu \mathrm{g} / \mathrm{kg}$ (fig. 6b). Ketamine (300 $\mu \mathrm{g} / \mathrm{kg}$ ) notably suppressed poly I:C-induced spinal microglia activation (fig. 6d).

All of these results suggest that inhibiting TLR3 activation could be an underlying mechanism of intrathecal ketamine in SNL-induced neuropathic pain. 

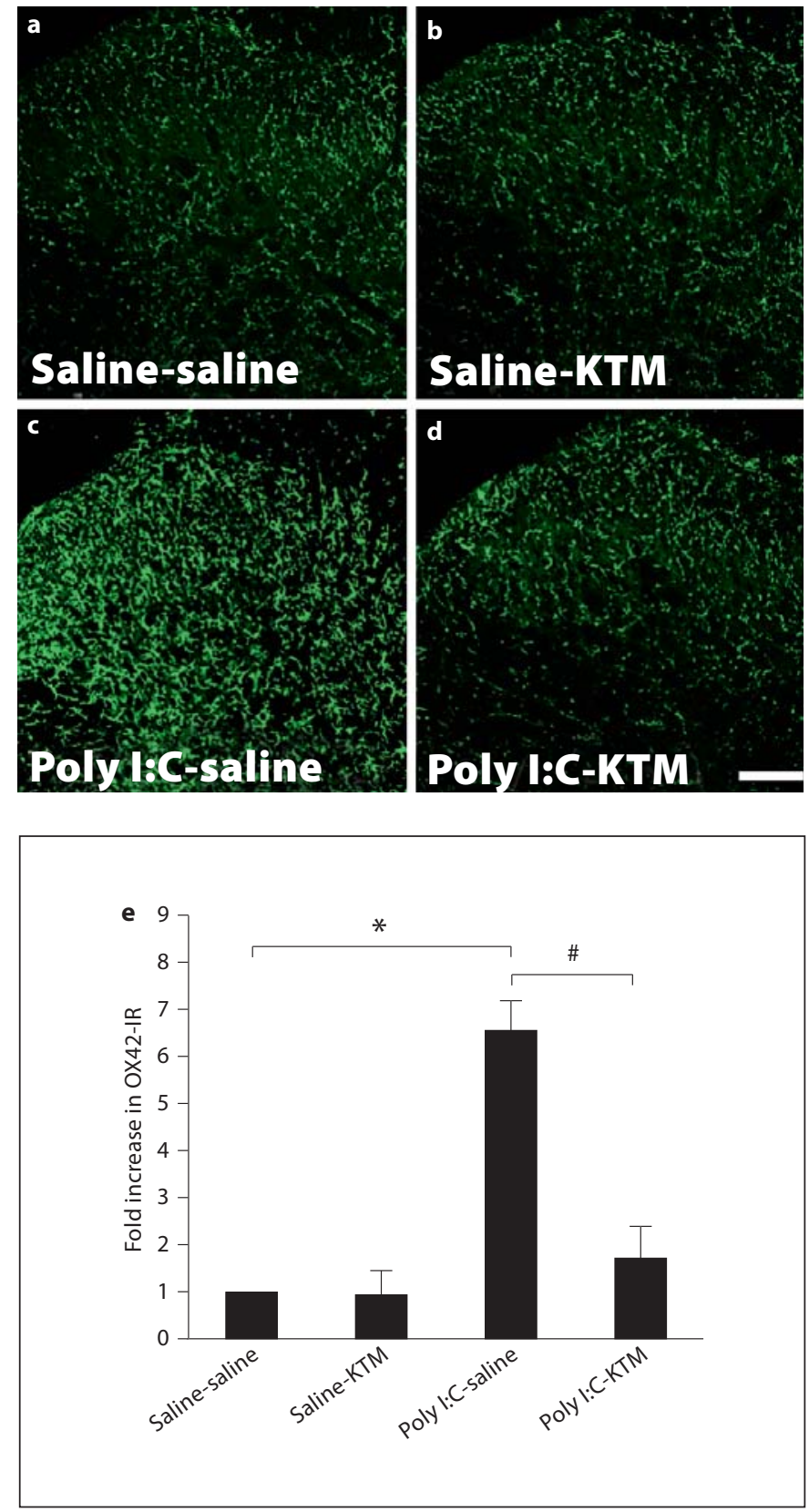

Fig. 6. Effect of intrathecal ketamine (KTM) on poly I:C injectioninduced spinal microglia activation. Poly I:C (100 $\mu \mathrm{g})$ injection induced a distinguished spinal microglia activation confirmed by the increased OX42 expression (c). Intrathecal ketamine (300 $\mu \mathrm{g} /$ $\mathrm{kg}$ ) suppressed poly I:C-induced microglia activation (d). e Statistical analysis of spinal microglia activation after different treatments with the density of OX42 expression. * and ${ }^{\#}$ indicate a statistical difference with $\mathrm{p}<0.05$ between groups. There were 6 rats in each group. Scale bar $=100 \mu \mathrm{m}$.

\section{Discussion}

The present study suggests that intrathecal injection of ketamine could relieve SNL-induced mechanical allodynia, probably by suppressing TLR3-induced spinal microglia activation during the initiation of SNL-induced neuropathic pain. Moreover, it may be one of the underlying mechanisms of the analgesic effect of intrathecal ketamine on peripheral nerve injury-induced neuropathic pain.

Both clinical and animal studies have shown that ketamine can be applied for treating many kinds of chronic pain, such as neuropathic pain, cancer pain, and complex regional pain syndrome $[4,5,37]$. The present results show that a low dose of ketamine $(30 \mu \mathrm{g} / \mathrm{kg})$ administration did not affect the pain threshold of the neuropathic rats, while $100 \mu \mathrm{g} / \mathrm{kg}$ ketamine showed obvious effects on mechanical allodynia. However, high-dose ketamine $(300 \mu \mathrm{g} / \mathrm{kg})$ administration raised the SNL-induced mechanical pain threshold without any impairment on motor function. These results confirm that ketamine is effective in treating peripheral nerve injury-induced mechanical allodynia, which is accordant with previous reports $[5,38]$. Although the analgesic effect of ketamine is undoubted, the underlying mechanisms are not yet fully understood.

Numerous reports have confirmed that spinal glial cells (microglia and astrocytes) are essential and sufficient for the development of peripheral nerve injury-induced neuropathic pain [1, 14, 17], and an interesting in vitro study demonstrated that ketamine can inhibit LPSinduced microglial activation via downregulation of the inflammatory factor TNF- $\alpha$ [27]. Our present study demonstrates that intrathecal ketamine could inhibit microglial activation with OX42 downregulation after SNL. Peripheral nerve injury induced spinal microglia activation as early as 1 day after the lesion [16]. Activated spinal microglia could release many inflammatory cytokines and chemokines which seriously facilitate the lesion [15]. It has been confirmed that peripheral nerve injury-induced spinal microglial activation is one of the key factors in the initiation of neuropathic pain development [34]. Therefore, the present result of inhibiting SNL-induced spinal microglial activation might contribute to the analgesic effect of intrathecal ketamine on mechanical allodynia. But, how does ketamine act on microglia to exert the inhibiting effect?

TLRs play an essential role in innate immune responses and in the initiation of adaptive immune responses [21]. TLRs, especially TLR2-4, have been reported as im- 
portant for the development of neuropathic pain [21,39, 40]. Previous studies have shown that SNL induces neuropathic pain with a significant upregulation of TLR2-4 $[39,40]$. TLR-deficient mice display significantly attenuated behavioral hypersensitivity and decreased expression of spinal glial activation and proinflammatory cytokines [41]. Microglia constitutively express a wide range of TLR2-4 at high levels [42]. A previous study [21] observed that intrathecal administration of TLR3 antisense oligodeoxynucleotide suppressed SNL-induced mechanical allodynia and decreased the phosphorylation of p38 MAPK, but not extracellular signal-regulated protein kinases $1 / 2$, in spinal microglia. These results suggest that TLRs have a substantial role in the activation of spinal glial cells and the development of mechanical allodynia after peripheral nerve injury. Interestingly, studies have demonstrated that ketamine could inhibit proinflammatory gene expression, such as TNF- $\alpha$, IL-1 $\beta$, and IL-6, among others, possibly by suppressing TLR-mediated signal transduction [27-30]. Moreover, other in vitro studies have suggested that ketamine could inhibit microglia activation and block MAPK pathway activation, which are induced by LPS, a ligand for TLR4 $[26,27]$. The present study observed that ketamine could suppress TLR3 agonist-induced mechanical allodynia and spinal dorsal horn microglia activation, which was accordant with these previous reports in this respect. Since TLR3 contributes greatly to SNL-induced spinal microglia p38 MAPK activation and the development of mechanical allodynia, ketamine might act on TLR3 located on microglia and thus inhibit microglia p38 activation after SNL.

Ketamine is known to be a nonselective NMDA receptor antagonist, and a recent study reported that the NMDA receptor subunit NR1 is phosphorylated after peripheral nerve injury [43]. Moreover, a study indicated that NMDA injection leads to increased p-p38 MAPK immunoreactivity predominantly in spinal microglia [44]. This report suggested that the microglial NMDA-pp38 pathway is involved in spinal nociceptive processing. Our present study demonstrated that ketamine application could effectively depress the spinal microglial p-p38 level and relieve mechanical allodynia induced by SNL. Therefore, ketamine could possibly directly act on the microglial NMDA-p-p38 pathway to suppress spinal microglial activation.

In addition to this possibility, ketamine could suppress SNL-induced spinal microglial activation through the NMDA receptor indirectly. The NMDA receptor mainly distributes in the superficial dorsal horn, which has a much closer relationship with neuropathic pain
[45]. Spinal NMDA receptor phosphorylation correlates with the presence of neuropathic signs following peripheral nerve injury in rats [46]. Meanwhile, it has been reported that NMDA receptor activation could facilitate neuronal nitric oxide (NO) release, which contributes to the progression of pain transmission after nerve injury [47]. It has also been reported that inhibition of spinal neuronal $\mathrm{NO}(\mathrm{nNO})$ synthesis by the selective inhibitor of neuronal NO synthesis (nNOS) could suppress spinal microglia activation by attenuating p38 MAPK pathway activation [48]. This suggests that suppressing $\mathrm{nNO}$ signals to microglia leads to the downregulation of microglial p38 MAPK pathway activation, which is accordant with the findings of the present study that intrathecal NMDA antagonist ketamine could inhibit SNL-induced spinal microglia activation and downregulate microglial p38 MAPK pathway activation. Such p38 MAPK activation in microglia is consistent with a potential role in the development of neuropathic pain, which was verified by a previous report [16].

It could be concluded that the NMDA-nNO-microglia-p38 pathway plays an important role in the development of peripheral nerve injury-induced neuropathic pain. Therefore, blocking NMDA-nNO-microglia-p38 pathway activation, to some extent, could be the indirect action of intrathecal ketamine on inhibiting SNL-induced microglia activation.

In conclusion, our present study indicates that inhibiting TLR3-induced spinal microglia p38 MAPK pathway activation after SNL could be one of the antiallodynic mechanisms of intrathecal ketamine at the spinal level. The present work could be a basis for ketamine application when treating neuropathic pain in the clinical setting.

\section{Acknowledgements}

This work was supported by grants from the National Natural Science Foundation of China (30901400, 30772073, 30771133, and 30971123), the Eleventh Five-Year Project of Science and Technology (06G093), the National Program of Basic Research of China (G2006CB500808), and the Program for New Century Excellent Talents in University (NCET-06-0931). Our thanks also go to Dr. Jerome Staal from the Menzies Research Institute Tasmania in Australia for his critical scientific opinions and help in English. 


\section{References}

$>1$ Tsuda M, Inoue K, Salter MW: Neuropathic pain and spinal microglia: a big problem from molecules in 'small' glia. Trends Neurosci 2005;28:101-107.

$>2$ Nadeson R, Tucker A, Bajunaki E, Goodchild CS: Potentiation by ketamine of fentanyl antinociception. 1. An experimental study in rats showing that ketamine administered by non-spinal routes targets spinal cord antinociceptive systems. Br J Anaesth 2002;88:685-691.

$>3$ Christoph T, Schiene K, Englberger W, Parsons CG, Chizh BA: The antiallodynic effect of NMDA antagonists in neuropathic pain outlasts the duration of the in vivo NMDA antagonism. Neuropharmacology 2006;51: 12-17.

-4 Kiefer RT, Rohr P, Ploppa A, Dieterich HJ, Grothusen J, Koffler S, Altemeyer KH, Unertl K, Schwartzman RJ: Efficacy of ketamine in anesthetic dosage for the treatment of refractory complex regional pain syndrome: an open-label phase II study. Pain Med 2008;9:1173-1201.

$\checkmark 5$ Hota D, Bansal V, Pattanaik S: Evaluation of ketamine, nimodipine, gabapentin and imipramine in partial sciatic nerve transection model of neuropathic pain in rat: an experimental study. Methods Find Exp Clin Pharmacol 2007;29:443-446.

6 Schnoebel R, Wolff M, Peters SC, Brau ME, Scholz A, Hempelmann G, Olschewski H, Olschewski A: Ketamine impairs excitability in superficial dorsal horn neurones by blocking sodium and voltage-gated potassium currents. Br J Pharmacol 2005; 146:826-833.

$>7$ Koizuka S, Obata H, Sasaki M, Saito S, Goto F: Systemic ketamine inhibits hypersensitivity after surgery via descending inhibitory pathways in rats. Can J Anaesth 2005;52: 498-505.

$>8$ Abelson KS, Goldkuhl RR, Nylund A, Hoglund AU: The effect of ketamine on intraspinal acetylcholine release: involvement of spinal nicotinic receptors. Eur J Pharmacol 2006;534:122-128.

$>9$ Hevers W, Hadley SH, Luddens H, Amin J: Ketamine, but not phencyclidine, selectively modulates cerebellar $\mathrm{GABA}(\mathrm{A})$ receptors containing alpha 6 and delta subunits. J Neurosci 2008;28:5383-5393.

-10 Rahman W, Suzuki R, Webber M, Hunt SP, Dickenson AH: Depletion of endogenous spinal 5-HT attenuates the behavioural hypersensitivity to mechanical and cooling stimuli induced by spinal nerve ligation. Pain 2006;123:264-274.

11 Aicher SA, Sharma S, Cheng PY, Pickel VM: The N-methyl-D-aspartate (NMDA) receptor is postsynaptic to substance P-containing axon terminals in the rat superficial dorsal horn. Brain Res 1997;772:71-81.
12 Muller T, Fritschy JM, Grosche J, Pratt GD, Mohler H, Kettenmann H: Developmental regulation of voltage-gated $\mathrm{K}+$ channel and GABAA receptor expression in Bergmann glial cells. J Neurosci 1994;14:2503-2514.

13 Holdridge SV, Armstrong SA, Taylor AM, Cahill CM: Behavioural and morphological evidence for the involvement of glial cell activation in delta opioid receptor function: implications for the development of opioid tolerance. Mol Pain 2007;3:7.

14 Watkins LR, Milligan ED, Maier SF: Spinal cord glia: new players in pain. Pain 2001;93: 201-205.

15 Coull JA, Beggs S, Boudreau D, Boivin D, Tsuda M, Inoue K, Gravel C, Salter MW, De Koninck Y: BDNF from microglia causes the shift in neuronal anion gradient underlying neuropathic pain. Nature 2005;438:10171021.

16 Jin SX, Zhuang ZY, Woolf CJ, Ji RR: p38 mitogen-activated protein kinase is activated after a spinal nerve ligation in spinal cord microglia and dorsal root ganglion neurons and contributes to the generation of neuropathic pain. J Neurosci 2003;23:4017-4022.

17 Scholz J, Woolf CJ: The neuropathic pain triad: neurons, immune cells and glia. Nat Neurosci 2007;10:1361-1368.

18 Watkins LR, Milligan ED, Maier SF: Glial activation: a driving force for pathological pain. Trends Neurosci 2001;24:450-455.

19 Zhuang ZY, Wen YR, Zhang DR, Borsello T, Bonny C, Strichartz GR, Decosterd I, Ji RR: A peptide c-Jun N-terminal kinase (JNK) inhibitor blocks mechanical allodynia after spinal nerve ligation: respective roles of JNK activation in primary sensory neurons and spinal astrocytes for neuropathic pain development and maintenance. J Neurosci 2006; 26:3551-3560.

20 Terayama R, Omura S, Fujisawa N, Yamaai T, Ichikawa H, Sugimoto T: Activation of microglia and p38 mitogen-activated protein kinase in the dorsal column nucleus contributes to tactile allodynia following peripheral nerve injury. Neuroscience 2008;153:12451255.

21 Obata K, Katsura H, Miyoshi K, Kondo T, Yamanaka H, Kobayashi K, Dai Y, Fukuoka T, Akira S, Noguchi K: Toll-like receptor 3 contributes to spinal glial activation and tactile allodynia after nerve injury. J Neurochem 2008;105:2249-2259.

22 Detloff MR, Fisher LC, McGaughy V, Longbrake EE, Popovich PG, Basso DM: Remote activation of microglia and pro-inflammatory cytokines predict the onset and severity of below-level neuropathic pain after spinal cord injury in rats. Exp Neurol 2008;212: 337-347.

23 Inoue K: The function of microglia through purinergic receptors: neuropathic pain and cytokine release. Pharmacol Ther 2006;109: 210-226.
24 Kawasaki Y, Zhang L, Cheng JK, Ji RR: Cytokine mechanisms of central sensitization: distinct and overlapping role of interleukin1beta, interleukin-6, and tumor necrosis factor-alpha in regulating synaptic and neuronal activity in the superficial spinal cord. J Neurosci 2008;28:5189-5194.

-25 Ohtori S, Takahashi K, Moriya H, Myers RR: TNF-alpha and TNF-alpha receptor type 1 upregulation in glia and neurons after peripheral nerve injury: studies in murine DRG and spinal cord. Spine 2004;29:10821088.

-26 Chang Y, Lee JJ, Hsieh CY, Hsiao G, Chou DS, Sheu JR: Inhibitory effects of ketamine on lipopolysaccharide-induced microglial activation. Mediators Inflamm 2009;2009: 705379.

27 Shibakawa YS, Sasaki Y, Goshima Y, Echigo N, Kamiya Y, Kurahashi K, Yamada Y, Andoh T: Effects of ketamine and propofol on inflammatory responses of primary glial cell cultures stimulated with lipopolysaccharide. Br J Anaesth 2005;95:803-810.

28 Chang HC, Lin KH, Tai YT, Chen JT, Chen RM: Lipoteichoic acid-induced TNF-alpha and IL-6 gene expressions and oxidative stress production in macrophages are suppressed by ketamine through downregulating Toll-like receptor 2-mediated activation of ERK1/2 and NFkappaB. Shock 2010;33: 485-492.

29 Yu M, Shao D, Yang J, Feng S, Xu J: Ketamine suppresses intestinal TLR4 expression and NF-kappaB activity in lipopolysaccharidetreated rats. Croat Med J 2006;47:825-831.

30 Chen TL, Chang CC, Lin YL, Ueng YF, Chen RM: Signal-transducing mechanisms of ketamine-caused inhibition of interleukin-1 beta gene expression in lipopolysaccharidestimulated murine macrophage-like Raw 264.7 cells. Toxicol Appl Pharmacol 2009; 240:15-25.

31 Zimmermann M: Ethical guidelines for investigations of experimental pain in conscious animals. Pain 1983;16:109-110.

-32 Mei X, Wang W, Wang W, Li Y, Zhang H, Wu S, Li Y, Xu L: Inhibiting astrocytic activation: a novel analgesic mechanism of ketamine at the spinal level? J Neurochem 2009;109: 1691-1700.

33 Kim SH, Chung JM: An experimental model for peripheral neuropathy produced by segmental spinal nerve ligation in the rat. Pain 1992;50:355-363.

34 Zhuang ZY, Gerner P, Woolf CJ, Ji RR: ERK is sequentially activated in neurons, microglia, and astrocytes by spinal nerve ligation and contributes to mechanical allodynia in this neuropathic pain model. Pain 2005;114: 149-159. 
>35 Guo W, Wang H, Watanabe M, Shimizu K, Zou S, LaGraize SC, Wei F, Dubner R, Ren K: Glial-cytokine-neuronal interactions underlying the mechanisms of persistent pain. J Neurosci 2007;27:6006-6018.

36 Wang W, Wang W, Mei X, Huang J, Wei Y, Wang Y, Wu S, Li Y: Crosstalk between spinal astrocytes and neurons in nerve injuryinduced neuropathic pain. PLoS One 2009; 4:e6973.

\$37 Lauretti GR, Lima IC, Reis MP, Prado WA, Pereira NL: Oral ketamine and transdermal nitroglycerin as analgesic adjuvants to ora morphine therapy for cancer pain management. Anesthesiology 1999;90:1528-1533.

>38 Gammaitoni A, Gallagher RM, Welz-Bosna M: Topical ketamine gel: possible role in treating neuropathic pain. Pain Med 2000;1: 97-100.

-39 Bettoni I, Comelli F, Rossini C, Granucci F, Giagnoni G, Peri F, Costa B: Glial TLR4 receptor as new target to treat neuropathic pain: efficacy of a new receptor antagonist in a model of peripheral nerve injury in mice. Glia 2008;56:1312-1319.
40 Kim D, Kim MA, Cho IH, Kim MS, Lee S, Jo EK, Choi SY, Park K, Kim JS, Akira S, Na HS, Oh SB, Lee SJ: A critical role of toll-like receptor 2 in nerve injury-induced spinal cord glial cell activation and pain hypersensitivity. J Biol Chem 2007;282:14975-14983.

41 Cao L, Tanga FY, Deleo JA: The contributing role of CD14 in toll-like receptor 4 dependent neuropathic pain. Neuroscience 2009;158: 896-903.

42 Bsibsi M, Ravid R, Gveric D, van Noort JM: Broad expression of Toll-like receptors in the human central nervous system. J Neuropathol Exp Neurol 2002;61:1013-1021.

43 Daulhac L, Maffre V, Mallet C, Etienne M, Privat AM, Kowalski-Chauvel A, Seva C, Fialip J, Eschalier A: Phosphorylation of spinal N-methyl-D-aspartate receptor NR1 subunits by extracellular signal-regulated kinase in dorsal horn neurons and microglia contributes to diabetes-induced painful neuropathy. Eur J Pain 2011;15:169.e1-169.e12.

44 Svensson CI, Hua XY, Protter AA, Powell HC, Yaksh TL: Spinal p38 MAP kinase is necessary for NMDA-induced spinal PGE(2) release and thermal hyperalgesia. Neuroreport 2003;14:1153-1157.
5 Chizh BA, Headley PM, Tzschentke TM: NMDA receptor antagonists as analgesics: focus on the NR2B subtype. Trends Pharmacol Sci 2001;22:636-642.

46 Ultenius C, Linderoth B, Meyerson BA, Wallin J: Spinal NMDA receptor phosphorylation correlates with the presence of neuropathic signs following peripheral nerve injury in the rat. Neurosci Lett 2006;399: 85-90.

47 Yonehara N, Kudo C, Kamisaki Y: Involvement of NMDA-nitric oxide pathways in the development of tactile hypersensitivity evoked by the loose-ligation of inferior alveolar nerves in rats. Brain Res 2003;963:232243.

48 Liu W, Wang CH, Cui Y, Mo LQ, Zhi JL, Sun SN, Wang YL, Yu HM, Zhao CM, Feng JQ, Chen PX: Inhibition of neuronal nitric oxide synthase antagonizes morphine antinociceptive tolerance by decreasing activation of p38 MAPK in the spinal microglia. Neurosci Lett 2006;410:174-177. 